Avrupa Bilim ve Teknoloji Dergisi

Özel Sayı 34, S. 42-52, Mart 2022

(C) Telif hakkı EJOSAT'a aittir

Arastırma Makalesi

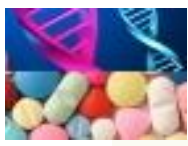

www.ejosat.com ISSN:2148-

2683
European Journal of Science and Technology

Special Issue 34, pp. 42-52, March 2022

Copyright (C) 2022 EJOSAT

Research Article

\title{
Computer Aided Deep Learning Based Assessment of Stroke from Brain Radiological CT Images
}

\author{
Ali Berkan Ural* \\ ${ }^{1 *}$ Electrical Electronics Engineering, Biomedical, Kafkas University, Kars, Turkey, (ORCID: 0000-0001-5176-9280), berkan.ural@kafkas.edu.tr
}

(2nd International Conference on Applied Engineering and Natural Sciences ICAENS 2022, March 10-13, 2022)

(DOI: 10.31590/ejosat.1063356)

\begin{abstract}
ATIF/REFERENCE: Ural, A.B. (2022). Computer Aided Deep Learning Based Assessment of Stroke from Brain Radiological CT
\end{abstract} Images. European Journal of Science and Technology, (34), 42-52.

\begin{abstract}
The aim of the study is to detect the abnormal area(s) from brain CTs of stroke patients using Image Processing and to accurately evaluate the stroke changes in brain tissues among patients with Deep Learning models in MATLAB $2019 \mathrm{~b}$ interface. 1000 patients (500 stroke suspected, 500 healthy participants) were chosen between 25 and 75 age ranges from TOBB ETU and Y1ldirım Beyazit University Hospitals according to the ethics committee certificate. For this study, for increasing the accuracy and eliminating the redundancy, from the image data of the patients, only lateral and 4th ventricle CT images were used. Firstly, these images were processed via Image Processing methods (Image Acquisition, Preprocessing, Thresholding, Segmentation, Morphological Operations etc.). After these methods, the resulted lateral ventricle image was split into 6 specific areas and 4th ventricle image was split into 14 specific areas like automated computerized Alberta Stroke Scoring, respectively. For 1000 images, totally 20x1000=20000 pieces of CT subimages were obtained with the specific class names (as healthy and stroke) and were used as the input of Artificial Intelligence (AI) and Deep Learning (DL) models (optimized ANN with Levenberg-Marquardt method and CNN). This approach can give an important chance to the doctors for supporting their results with a decision support system, speeding up the diagnosis time and also decreasing the possible rate of misdiagnosis.
\end{abstract}

Keywords: Artificial Intelligence, Deep Learning, Stroke Diagnosis, CAD, Stroke Prevention

\section{İnmenin Beyin Radyolojik BT Görüntülerinden Bilgisayar Destekli Derin Öğrenmeye Dayalı Değerlendirilmesi}

Öz

Çalışmanın amacı, MATLAB 2019b arayüzünde Derin Öğrenme modelleri ile inme hastalarının beyin BT'lerinden Görüntü İşleme kullanarak anormal alan(lar)1 tespit etmek ve hastalarda beyin dokularındaki inme değişikliklerini doğru bir şekilde değerlendirmektir. TOBB ETÜ ve Yıldırım Beyazıt Üniversitesi Hastanelerinden 25-75 yaş aralığında 1000 hasta (500 inme şüphelisi, 500 sağlıklı katılımc1) etik kurul sertifikasına göre seçilmiştir. Bu çalışma için hastaların görüntü verilerinden doğruluğu artırmak ve fazlalığı ortadan kaldırmak için sadece lateral ve 4. ventrikül BT görüntüleri kullanıldı. İlk olarak bu görüntüler Görüntü İşleme yöntemleri (Görüntü Toplama, Ön İşleme, Eşikleme, Segmentasyon, Morfolojik İşlemler vb.) ile işlenmiştir. Bu yöntemlerden sonra elde edilen lateral ventrikül görüntüsü 6 spesifik alana bölündü ve 4. ventrikül görüntüsü otomatik bilgisayarlı Alberta Stroke Skorlama gibi sırasıyla 14 spesifik alana bölündü. 1000 görüntü için, belirli sınıf adlarıyla (sağlıklı ve felçli olarak) toplam 20x1000=20000 adet BT alt görüntüsü elde edilmiş ve Yapay Zeka (AI) ve Derin Öğrenme (DL) modellerinin (Levenberg ile optimize edilmiş YSA) girdisi olarak kullanılmıştır. Marquardt yöntemi ve KSA). Bu yaklaşım, doktorlara sonuçlarını bir karar destek sistemi ile desteklemeleri, teşhis süresini hızlandırmaları ve olası yanlış teşhis oranlarını azaltmaları için önemli bir şans verebilir.

Anahtar Kelimeler: Yapay Zekâ, Derin Öğrenme, İnme Tanılama, Bilgisayar Destekli Tanı, İnme Önleme 


\section{Introduction}

Radiological imaging systems have commonly used for diagnosis of the health problems for many years. The usage of artificial intelligence and then improved versions of biomedical algorithms in medicine have gained importance in variety of areas [1]. There are many types of lesions in the brain, but especially in the analysis part of the stroke, radiological imaging such as Computerized Tomography (CT) has been chosen as the first imaging modality among doctors [2]. Computer Aided Diagnosis (CAD) systems has been soaringly applied in the field of neurosurgery. In the management phase of the lesions (especially stroke), CAD tools can obtain a vital role as a crucial support decision system in diagnosis, determining and scoring of the stroke in the brain tissues with using CT images of the patients $[3]$.

In medicine, especially in neurosurgery, there has been a scoring theory whose name is Alberta scoring for acute ischemic stroke [4]. In the medical schools, in the lectures which belong to the brain anatomy and neurosurgery, this theory has been told to the students by scientists [4-9]. But for years, in the pre-diagnosis phase of the acute stroke types; self-knowledge, experience and qualification have main roles. Lots of doctors have not chosen to use this theory practically. According to this reason, it is obvious with the statistical values that, in our country approximately $\% 20$ 25 of the decisions which belonged to the diagnosis of the ischemic stroke were wrong and this issue has given bigger unprecedented legal responsibilities to many doctors and health institutes. In this part, it is clearly seen that, the usage of CAD systems in this area might be a key factor in stroke management with special algorithms with computers and these systems can help doctors in the determining the therapeutic approach of stroke like support decision systems.

In radiology, X-ray imaging is generally used for scanning the affected part of the human body. Indeed, CT imaging modality can be defined as the developed version of the X-ray imaging in detail. However X-ray is faster, easier and cheaper imaging method, recognizing and diagnosing stroke infarcts might decrease the future mortality rate.

Computerized Tomography (CT) has generally used as one of the common methods to diagnose acute stroke [10]. Deep Learning based automated CT image analyses for the detection, interpretation and analyzing the stroke and to distinguish infarcts from the others.

We analyzed studies from 2000 and 2019, in fact all available studies in the literature and there are some studies which belong to diagnosis of the brain lesions and stroke with CAD systems. Indeed, B. URAL achieved an important study with other coauthors in May 2019 whose name was "An improved computer based diagnosis system for early detection of abnormal lesions in the brain tissues with using magnetic resonance and computerized tomography images" [11]. According to the study, the improved automated detection and interpretation CAD approach for brain masses (tumor/lesion) was mainly aimed via using Magnetic Resonance Imaging and Computerized Tomography. Also, according to the literature; Fei et al. developed an AI learningbased system for automated segmentation of the lungs via chest CT [12]. Indeed, Shuai et al., achieved a study that was based on
COVID-19 changes radiologically from CT scans. They developed a deep learning method that can extract the graphical features of the lungs of the infected patients [13].

According to the situations given above, the originality of this system against other $\mathrm{CAD}$ studies in literature is more fast and more accurate detection of the stroke in the brain tissues, welldeveloped analysis and interpretation-scoring algorithms for helping the doctors for improving the accuracy of the obtained results via using specifically improved Image Processing, Pattern Recognition, Decision Making Process with Artificial Intelligence and Deep Learning in MATLAB. Indeed, this system can be developed to new well-designed $\mathrm{CAD}$ approaches that will allow the faster identification, scoring and interpretation of the other lesions in human brain in addition to ischemic stroke.

In this study, we have proposed a computer based biomedical diagnosis approach that consists from automated detection with specific image processing methods and deep analyses on stroke suspected CT dataset with trend AI and DL models via MATLAB $2019 \mathrm{~b}$ interface. These models are the optimized version of Artificial Neural Network (ANN) with Levenberg-Marquardt algorithm and Convolutional Neural Network (CNN). First, lateral and 4th ventricle CT images were processed by Image Processing methods. Second, the resulted image for lateral ventricle was split into 6 specific areas and for 4th ventricle was split into 14 specific areas based on automated and computerized Alberta Stroke Scoring, respectively. For 1000 images, totally $20 \times 1000=20000$ pieces of CT database were obtained and used with the classes of healthy and stroke as the input of AI and DL models (CNN and ANN with Levenberg-Marquardt method). For 20000 images, $\% 80$ of the images were used as training and \%20 of the images were used as testing in Deep Learning. Also, the novelty of this work can be summarized as according to the MATLAB ANN and CNN-motivated and optimized deep convolutional neural network models, these are more effective pre-trained models than the others. Also, our hybrid methods are more powerful tahn the techniques in the past. Indeed, in the stroke scoring part, brain scoring field boundaries than can analyze and detect stroke in a broader framework and stroke can be detected with higher success with this analysis. Moreover, with using the specific AI and DL models, fast and hybrid classification is achieved with 5-fold cross validation.

\section{Material and Method}

\subsection{Dataset of the Study}

This study can be classified as the retrospective type of study. The dataset is included totally 1000 images; 500 stroke suspected and 500 healthy participants' images, especially axial scan data of the images was used and these images were chosen between 25 and 75 age ranges from TOBB ETU and Y1ldırım Beyazıt University Hospitals according to the obtained ethics committee certificate (from TOBB ETU Clinical Research Ethical Committee with the protocol number of KAEK-118/019). Also, all images were assessed by Dr. Pınar Akdemir Özışık from Yıldırım Beyazit University, Medical School, Deparment of Neurosurgery in detail. The anonymized radiological image clusters were stored in DICOM format and used in jpeg format. 


\subsection{Methodology}

This study was generally performed in MATLAB 2019b interface. The proposed study consisted from two fundamental parts was a computer-based, preliminary diagnosis approach that allows for fast detection, early interpretation and accurate prediction of the stroke suspected patients. The goal of the approach was helping doctors and radiologists optimally with a support mechanism. Indeed, the first part of the approach was detecting the abnormal/infected area (ROI) with using specific common image processing methods. Then, the other part was interpretation, automated scoring and prediction of the CT data with using the optimized version of ANN with LevenbergMarquardt (LM) algorithm and CNN model and finally these models were compared according to the performance metrics. In this step, normal and infected images were predicted with these models and ROC analysis results were compared. During 5-fold cross validation, patients were randomly divived into 5 sets. In each fold, the 5 sets were split by a ratio of $3: 1: 1$, with 3 sets used for training, 1 for validation and 1 for testing. No test cases were part of the training or validation sets for any of the 5 folds in the cross validation. The processes were given in Figure 1 and 2, respectively.

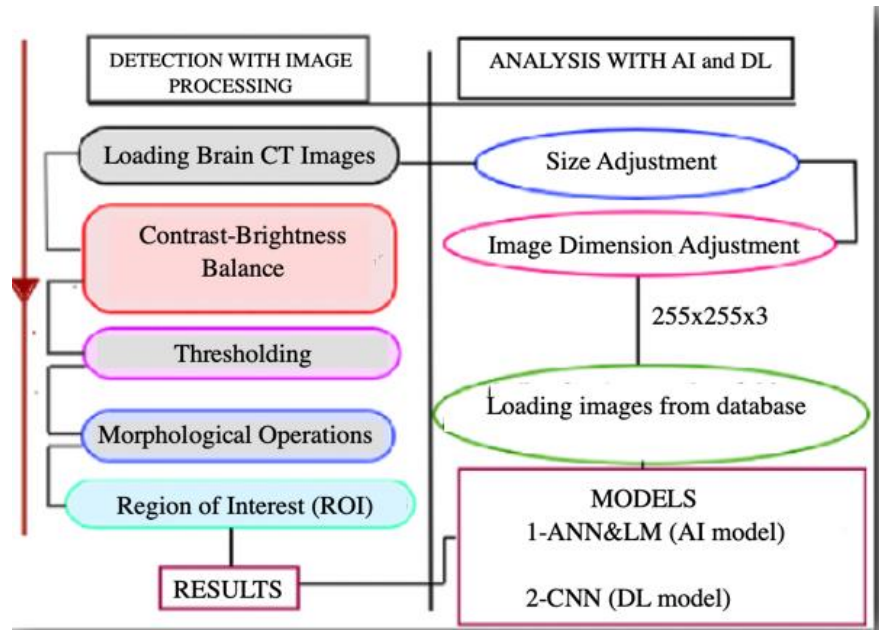

Fig. 1. Stroke detection and interpretation system (vers 1)

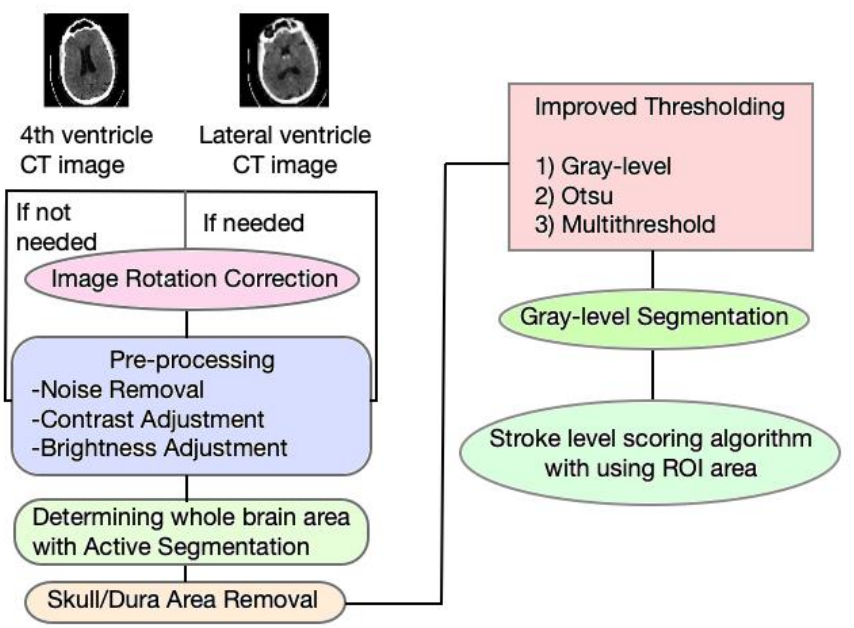

Fig. 2. Stroke detection and interpretation system (vers 2)

\subsection{Detection of Lesion(s) with Image Processing} e-ISSN: 2148-2683

\section{- Load CT image(s)}

In this stage, healthy and stroke suspected CT images were loaded to the software and these images were generally used in '.jpg' format for better image acquisition. Also, all images had different size values and all of them were re-sized in $255 \times 255(x 3)$ pixels and used in the gray-level format.

\section{- Image Filtering}

For the pre-processing stage, the first step is the filtering process for CT images which are chosen and uploaded to the interface of the system. The main objective in the filtering process is decreasing the level of possible noise with using Median and Gaussian filtering types [14]. For these types, according to the calculations, $4 \times 4$ filter was optimally chosen and applied to the images in this part and the results are stored in the system's memory [14].

\section{- Monitoring Contrast-Brightness Balance}

In this stage, stroke suspected CT images were re-balanced according to the parameters of contrast and brightness. For this case, Discrete Wavelet Transform were used for obtaining the contrast feature of the images [15]. In this step, with using the transform and "regionprops" method in MATLAB, the gray-comatrix was obtained with the contrast value from the gray-level images. Then, for all images, the contrast and brightness level was standardized in a specific optimal value ( $\mathrm{feat}=.208$ - this value was obtained after many practice), so dark images were obtained in the brighter versions and at the end of the process, the details of the images were more sharpened [16].

For this part of the study, 2-Dimensional Discrete Wavelet Transform (DWT) was used. This method was an advanced technique of signal and image processing. This was developed as an alternative version of the short time Fourier transform [17]. The main idea of DWT was to provide the representation of time and resolution properties. The 2-D DWT represented an image in related to a set of shifted and dilated wavelet functions of $\gamma^{L H}, \gamma^{H L}, \gamma^{H H}$ and the scaling functions $\emptyset^{L L}$ that form an orthonormal basis for $L^{2}\left(R^{2}\right)$. Given a l-scale DWT, an image $\mathrm{K}(\mathrm{a}, \mathrm{b})$ of NxN was decomposed as Equation (1) and (2) [17].

$\mathrm{K}(\mathrm{a}, \mathrm{b})=$

$\sum_{k, i=0}^{N_{l}-1} u_{l, k, i} \emptyset_{l, k, i}^{L L}(a, b) \sum_{B \in B} \sum_{l=1} \sum_{k, i=0}^{N-1} w_{l, k, i}^{B} \emptyset_{l, k, i}^{B}(a, b)$

$\emptyset_{l, k, i}^{L L}(a, b) \equiv 2^{-l / 2} \emptyset\left(2^{-l} \mathrm{a}-\mathrm{k}, 2^{-l} b-i\right), \emptyset_{l, k, i}^{B}(\mathrm{a}, \mathrm{b})$

$\emptyset_{l, k, i}^{B}(\mathrm{a}, \mathrm{b}) \equiv 2^{-l / 2} \emptyset^{B}\left(2^{-l} \mathrm{a}-\mathrm{k}, 2^{-l} b-i\right), B \in \mathrm{B}$

For these equations, LH, HL, HH were called wavelet or subbands.

\section{- Skull Removal Process}

This process is performed by the hybrid combination of the improved version of Gray-level Thresholding, Otsu method and Multi-level thresholding [18-19] and this is named as "Active Segmentation". 
The optimal threshold level for the segmentation process is obtained from automatically from uploaded images within the system and according to this step, brain area is clearly extracted from the whole image, so this can give an important chance to eliminate the other redundant areas in the images [20]. For the identification of brain boundaries, a green contour has used for each brain section with a continuously narrowing border region at 500 iterations. Indeed, morphological operations such as erotion, closing, eliminating boundary regions in the images are used for the last step of this process [21]. At the end of the process, the resulted images are successfully obtained in the skull/dura area removed version.

\section{- Improved Thresholding}

For this stage, the multi-hybrid improved version of thresholding which is combined from the Gray-level, Global, Otsu, Multithreshold methods has been achieved and used within the pre-segmentation part $[11,12,22,23,26]$. Contrast can be defined as the difference between the darkest and the brightest area in the image. Traditionally, one simple way for accomplishing the thresholding part is defining a range of brightness value in the original image, then selecting the pixels within the range as belonging to the foreground and rejecting all of other pixels to the background. In the formula of Equation (3) given below, $f$ is the main image and the $g$ is the resulted image after the thresholding for the specified value of $\mathrm{T}$. Indeed, in Figure 3, a graph version of thresholding for a single value is given.

$$
\begin{aligned}
& g(x, y)=0 ; \text { if } f(x, y)<T \\
& g(x, y)=1 ; \text { if } f(x, y)>T
\end{aligned}
$$

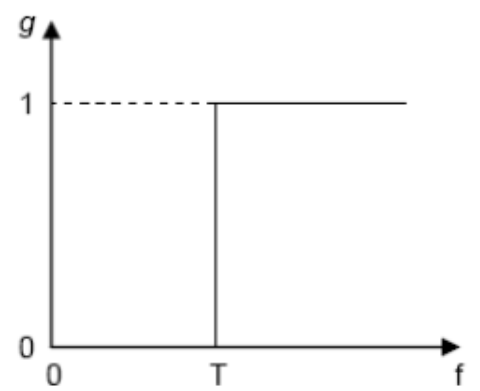

Fig. 3. Thresholding for a single specified value of $T$

Moreover, for the multilevel thresholding, the formula is given below in Equation (4) and (5). In the equation, $f$ is the original image and $\mathrm{g}$ is the resulted image. $\mathrm{c} 1$ and $\mathrm{c} 2$ are the value of the color channels of the image and $\mathrm{T} 1$ and $\mathrm{T} 2$ are the specified threshold values.

For the first channel (c1) of the 2D image;

$f(x, y) ;$ if $0 \leq c 1(x, y) \leq T 1$

$g(x, y)=0 ;$ if $c 1>T 1$

For the second channel (c2) of the 2D image;

$f(x, y) ;$ if $T 2 \leq c 2(x, y) \leq 255$

$g(x, y)=0 ;$ if $c 2<T 2$
At the end of the process, these given methods are combined successfully for the multi-hybrid version of thresholding process.

\section{- Morphological Operations}

In this step, a specifically defined disk structure element was used on the thresholded image and small unnecessary objects and some redundancies were eliminated in 16 size value [27]. The reason for choosing the disk type of structure element is the circled shape of the whole brain in CT.

\section{- Regional Based Analysis and Stroke Scoring Process}

For this stage, Alberta acute stroke scoring theory in medical literature was used and this theory was developed to the automated computerized version for identification of stroke. Doctors has generally used their knowledge and experience in the diagnosis phase of ischemic stroke in the diagnosis phase. According to the Alberta Stroke Scoring, from the lateral and 4th ventricle CT images, from the left and right parts of the brain, there are totally 20 different areas (M1, M2, M3, I, L, C, IC, M4, M5, M6 for left and right parts of the brain) for scoring ischemic stroke in detail [28]. Also, for this study, these specific areas (M1, M2, M3, I, L, C, IC, M4, M5, M6 for left and right parts of the brain) are automatically detected from brain images via Active Segmentation method. Moreover, the novelty of this study is that the specific area detection and definition progress have been achieved automatically, more broadly and completely (in Figure 5) than the Alberta stroke scoring theory (in Figure 4).

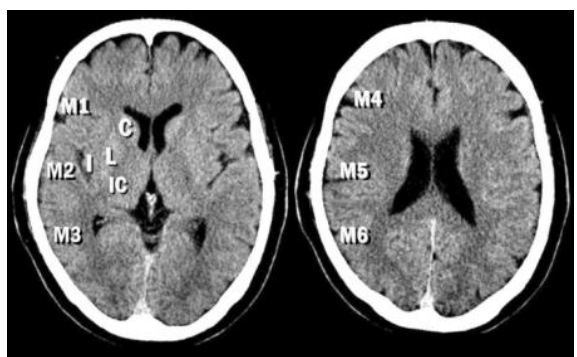

Fig. 4. Alberta scoring theory for identification of acute ischemic stroke

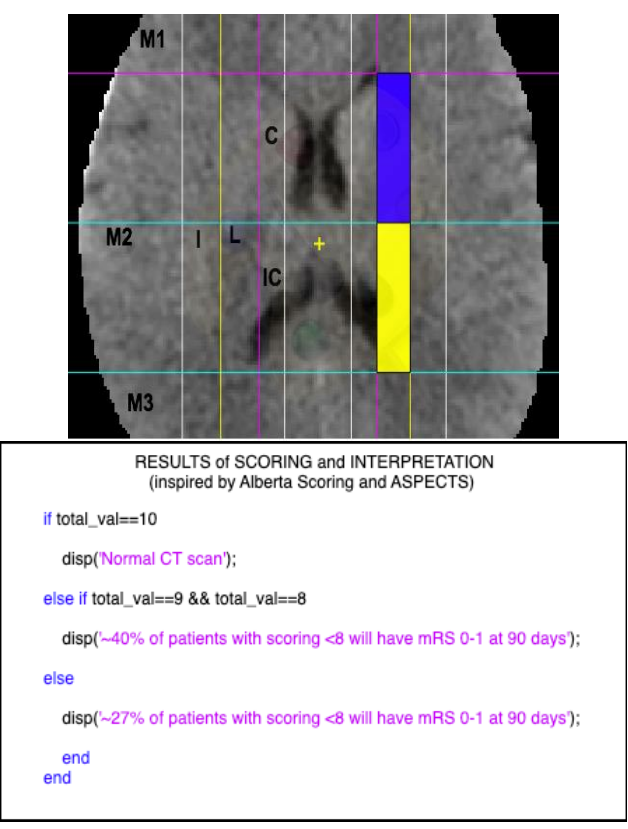


Fig. 5. Computer aided scoring and interpretation part for stroke

\subsection{Analysis/Interpretation Part with $\mathrm{AI}$ and DL}

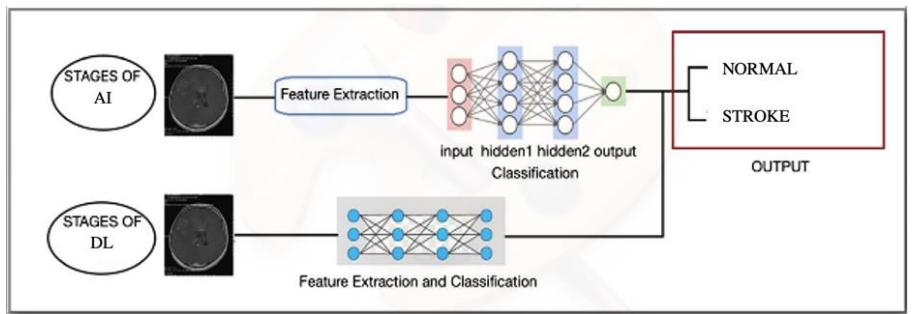

Fig. 6. Interpretation stages of Artificial Intelligence (AI) and Deep Learning (DL)

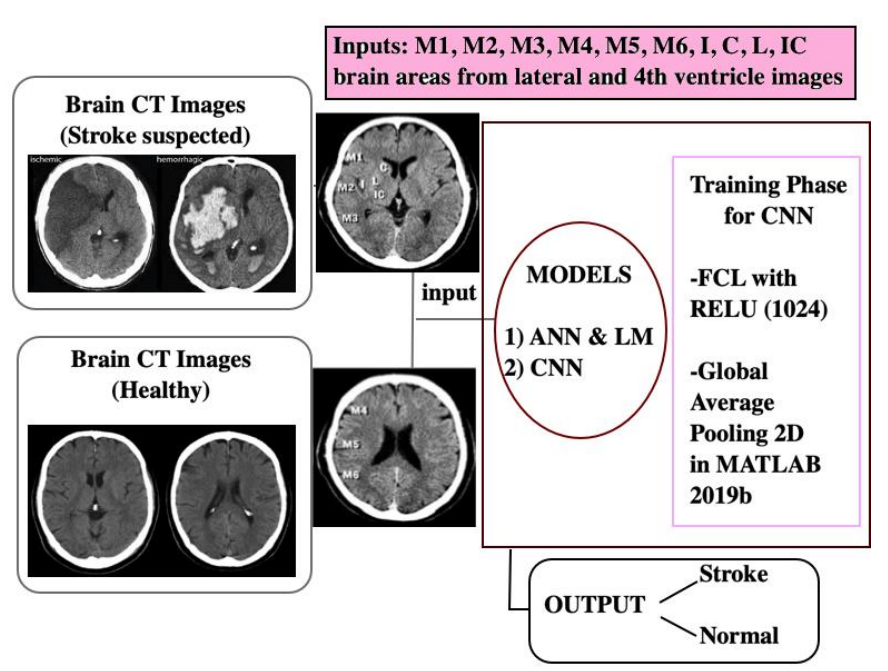

Fig. 7. Schematic representation of the interpretation and prediction of normal and stroke cases

\section{- Analysis/Interpretation with Artificial Neural Network (ANN)}

Artificial neural networks (ANNs) consist of simple elements working in parallel and mimic the biological nervous system. ANNs are computer systems developed with the aim of automatically realizing the capabilities of the human brain, such as the ability to generate and discover new information through learning, without any assistance [29].

In image processing, images can be represented in matrix form and elements of the matrix contains color information for a pixel [30]. The matrix of the image is used as input data set for ANN. The images with small dimensions provide easy and quick learning process for ANNs. Results proves that ANN can be successfully used to obtain models for image processing applications [31].

ANN based image processing has been widely used in many research fields such as geotechnics, intelligence and surveillance, mechanics, civil engineering. Face recognition technologies and driverless vehicles are among the simplest examples of image processing systems. Google Translate creates the image processing system in its translation application with machine learning and artificial neural networks algorithms.

ANNs play an important role in the application of medical image processing and disease detection. In this paper, Nftool of Matlab software was used to obtain ANN models in order to to e-ISSN: 2148-2683 classify sample stroke infarcts. 5, 10, 15 neurons were in the structure of an ANN that has a single hidden layer. ANN model was obtained/optimized by Levenberg-Marquardt was in training process of the models.

The Levenberg-Marquardt (LM) algorithm is also known as the damped least-squares method [32]. This algorithm is mainly developed to work specifically with loss functions. Indeed, this works without computing Hessian matrix exactly. Instead of this occasion, it works with the gradient vector and Jacobian matrix [32].

A loss function can be expressed as a sum of squared errors in Equation (6).

$$
f=\sum_{k=1}^{l} e_{k}^{2}
$$

In Eq. 5,1 is the number of the instances in the image data set.

According to the Jacobian matrix, we can define the loss function as the derivatives of the errors in Equation (7).

$$
J_{k, l}=\frac{d e_{k}}{d w_{l}} \quad(\text { for } \mathrm{k}=1, \quad 2, \quad \ldots, \quad \mathrm{i} \text { and } 1=1,2, \quad \ldots, \quad \mathrm{j})
$$

For Equation (6), $\mathrm{i}$ is the number of instances in the data set and $\mathrm{j}$ is the number of parameters in the neural network. Moreover, the size of the matrix can be defined as ixj.

Then, we can approximate the general Hessian matrix with the improvement of the parameters with Levenberg-Marquardt algorithm given in Equation (8).

$w^{(k+1)}=1 /\left[w^{(k)}-\left(J^{(k) T} \cdot J^{(k)}+d^{(k)} I\right] \cdot\left[2 J^{(k) T} \cdot e^{(k)}\right] . \quad(\right.$ for $\mathrm{k}=1$, $2, \ldots)$

When the damping parameter $\mathrm{d}$ is zero, this becomes gradient descent with a small training rate. Generally, $d$ is initialized to be large and if any iterations are resulted in a fail, $\mathrm{d}$ is automatically increased. Otherwise, as the loss function decreases, $d$ is decreased in order to approach the LM algorithm.

\section{- Analysis/Interpretation with Deep Learning}

Typically, Deep Learning was a sub-branch of the machine learning area, like the human brain [33]. For recent years, Deep Learning area and its methods has gained popularity in many study areas. Using Artificial Intelligence and Deep Learning has been very common in medicine and with using them, medical data could become more meaningful for scientist and doctors.

There were a lot of studies related to Deep Learning in literature. In contrary, in the analysis of medical dataset, the biggest problem was that there are limited number of dataset which doctors could use. Alike Artificial Intelligence, Deep Learning methods and models specifically needed lots of data. Labeling this data one by one was tough and time consuming. The biggest alternative for using Deep Learning models of Transfer Learning was that allows the training process with fewer data.

Based on Figure 6 and 7, Convolutional Neural Network (CNN) was one of the the basic models of Deep Learning. Indeed, Residual Neural Network was the more improved version model 
of CNN. When the network became deeper and bigger; this model prevented the common distortion. The input of the models was the $255 \times 255$ (x3) size of image and the output was mainly two classes of Stroke and Normal.

After capturing the approach with specific models, in the training phase, a nonlinear function was applied and by this function, every possible negative value was converted to 0 . The mentioned activation function was called as Rectified Linear Unit (ReLU) function with the formula in Equation (9).

$$
\mathrm{Y}=\max (0, \mathrm{X})
$$

Then, the specific pooling method was applied in variations of maximum, average and sum pooling [34]. In this approach, average pooling method was chosen and applied because of its efficiency. Average pooling, generally, reduced the dimensions of feature map while maintaining the most important feature values via sliding kernels over the rectified map and capturing the average values. Pooling was applied to make the data highly manageable with the dimension reduction.

For our network structure, preventing the overfitting, the images in the dataset were used with their rotated version from ($30,30)$. Then, for the DL model, CNN is chosen and used. In detail, as loss function, binary cross entropy function was used [35]. Also, the training data was trained with 120 epochs, the batch size of 40 and the learning rate of 0.0001 . Indeed, for the experimental part, dataset was randomly split into two different dataset with the percentage of $\% 80$ and $\% 20$ for training and testing. Indeed, for this model, $\mathrm{CNN}$ was created, then via the network, weight and bias values were created in the struct form. After using weight and bias as 0 value, learning process was begun and all results were stored and classification was achieved in every iteration.

In this study, we built a deep computerized network model with AI and DL models these models were used for training the whole images with pre-trained and hybrid models and classifying the images as Normal or Stroke.

\section{Results}

The experimental part of the presented study was achieved in MATLAB interface. The radiological images which were used in the system were mainly anonymized CT scans of the patients and the detailed medical interpretation and analyses were made by Dr. Pınar Akdemir Özışık from Yıldırım Beyazıt University.

Regarding the the proposed study, 1000 patients (500 stroke suspected, 500 healthy participants) were chosen between 25 and 75 age ranges from the hospitals of TOBB ETU and Yildırım Beyazit University according to the ethics committee certificate. Moreover, stroke cases were given in the graph form in Figure 8.

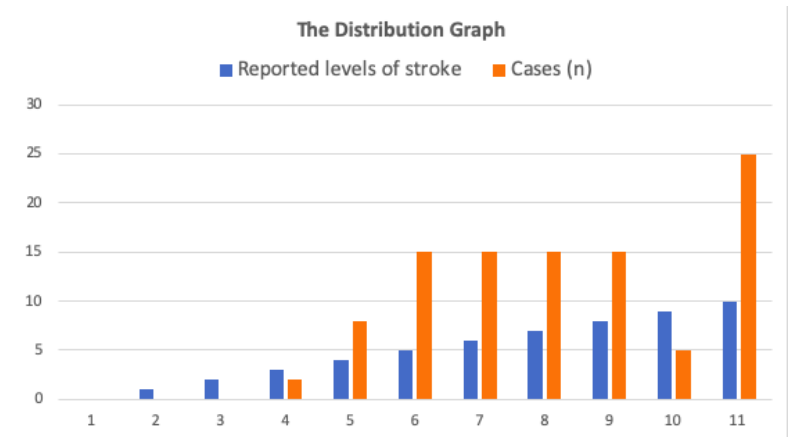

Fig. 8. Distribution of the some stroke levels of the patients with graphical version

This study was consisted from two important parts. The first part was about detecting abnormal area(s) with the combination of specific Image Processing methods. All of the images in the dataset were successfully analyzed and abnormal ROI(s) were obtained in approximately $30 \mathrm{sec}$, respectively. After the image processing part, in the scoring part, according to the Alberta Stroke Scoring, from the lateral and 4 th ventricle CT images, from the left and right parts of the brain, there are totally 20 different areas (M1, M2, M3, I, L, C, IC, M4, M5, M6 for left and right parts of the brain) for scoring ischemic stroke in detail. Also, for this study, these specific areas (M1, M2, M3, I, L, C, IC, M4, M5, M6 for left and right parts of the brain) are automatically detected from brain images via Active Segmentation method. Sample results were given in Figure 9 and 10.

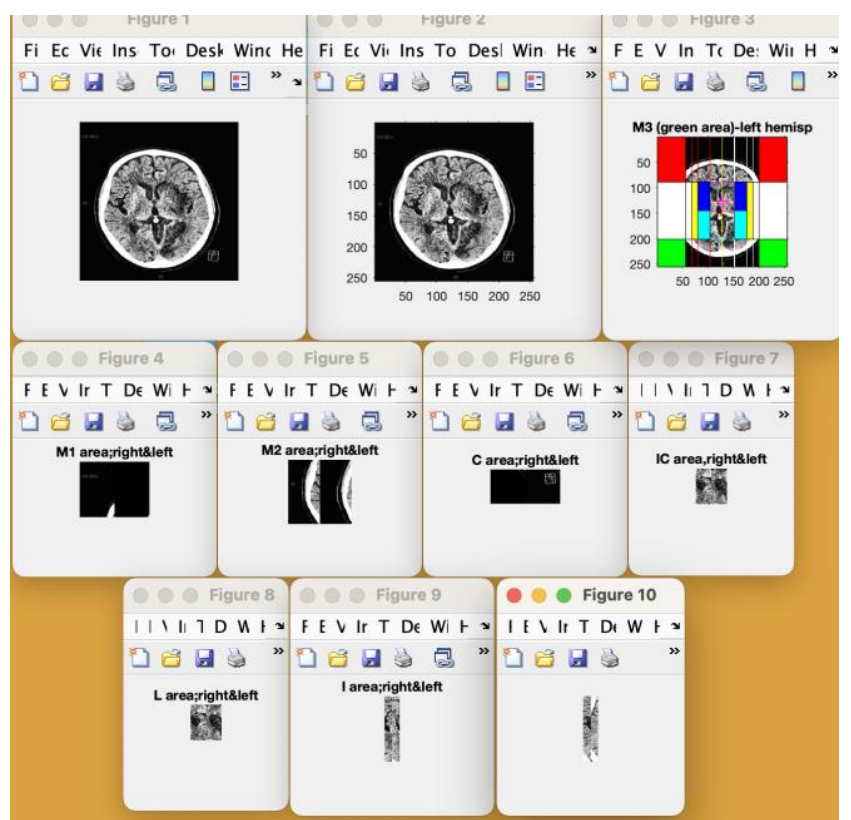

Fig. 9. After image processing, from stroke scoring process, results for 4th ventricle CT image 


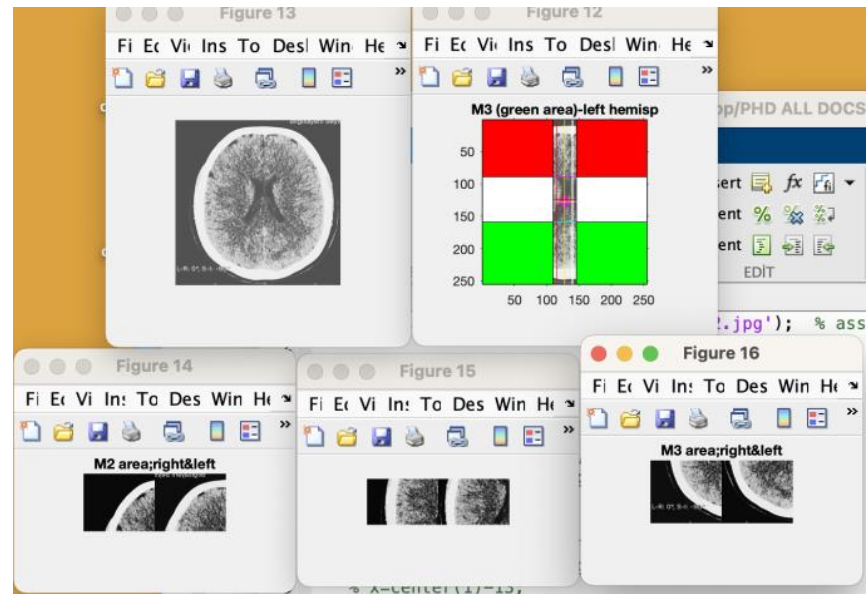

Fig. 10. After image processing, from stroke scoring process, results for lateral ventricle CT image

Indeed, the area under the curve (AUC) was calculated for the AI and DL models. The Dice Score Coefficient (DSC) reflects the amount of overlap between the prediction and the truth in the quation given below.

$\mathrm{DSC}=2 \mathrm{x}$ true positive $/(2 \times$ true positive + false positive + false negative)

This ranges from 0 to 1 and DSC is preferred to the AUC in tasks in which positive and negative samples are imbalanced, as for infarcted pixels/voxels in typical patients with stroke. For this stage, the ratio of accurate diagnosis for the image processing and stroke scoring system was examined and according to the equations given above; this value was calculated manually as 0.90 after rounding/approximation. Given that large lesion areas can bias the volume size predictions without affecting clinical importance, lesion volume predictions in cases with lesions smaller than $150 \mathrm{~mL}$ was analyzed. Then, this value was approved with the obtained value from ROC analysis. Moreover, it can be said that the whole system which was developed for the early diagnosis, interpretation and scoring of stroke, especially ischemic stroke can also detect and discriminate the normal and abnormal status of radiological images succesfully. In addition, the problematic regions tagged/marked by the physician on these radiological images as containing the stroke area overlapped with the problematic regions detected by our system on the same images. The detection process was thus performed with maximum performance, accuracy and rapidity with MATLAB.

According to the sensitivity analysis was evaluated by varying the threshold involvement value of each MCA region of the brain (M1, M2, M3, I, L, C, IC, M4, M5, M6) on expert-read $\mathrm{CT}$ as " $>\% 0$ " and " $>\% 50$ " involvement were used for the experimental analyses. It was clear that region-level agreement for our automated identifying method was better than other manual methods of Alberta Scoring.

The second part was related to the prediction/interpretation of stroke areas of suspected patients in MATLAB 2019b with using brain CT data. The improved optimized model of ANN with LM algorithm was used in the AI interpretation part. Indeed, the popular pre-trained model of $\mathrm{CNN}$ was used in the DL interpretation part.

From stroke patients included in the dataset (median age 45 years old, \%60 male) was consisted generally axial scan CTs. The e-ISSN: 2148-2683 image processing part was tested with using other sample infarcts in the case of area of decreased contrast and radiodensity. After the progress, it was obtained that the hypodensity became more apparent in the output images. The whole assessment was completed in one specific radiodensity value. According to the specific image processing methods, detecting and analyzing ROI processes were achieved successfully in approximately $15 \mathrm{sec}$.

According to the Figure 11, the mean deviation ranges were clearly given in a distribution graph form in detail. It was obvious that the distribution of the graph was compatible with the mean deviation distribution of scoring results of the test dataset.

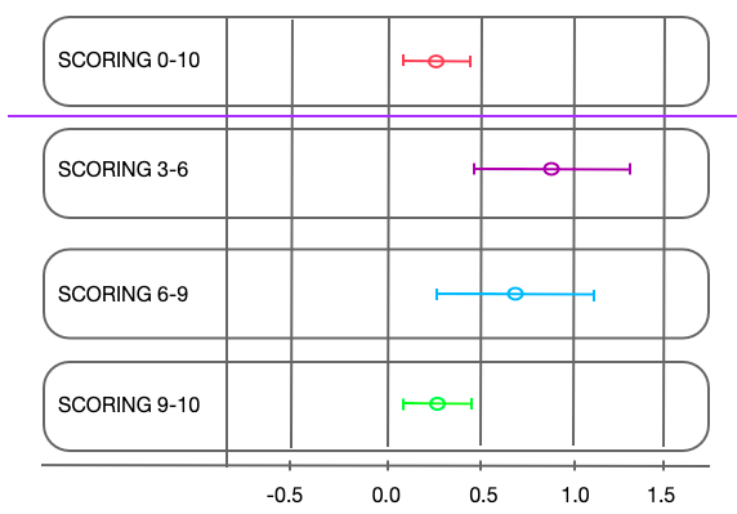

Fig. 11. Mean deviation distribution of the simulated scoring results of the test dataset

For 1000 images, totally $20 \times 1000=20000$ pieces of CT database were obtained and used in the specific classes (tagged folders as healthy and stroke) version as the input of Artificial Intelligence (AI) and Deep Learning (DL) models (CNN and preoptimized ANN with Levenberg-Marquardt method). For 20000 subimages, $\% 80$ of the images were used as training and $\% 20$ of the images were used as testing in DL part. Also, the selection criteria for the training and test clusters was the random choice. Then, if these images had different size value, the images were converted to the $255 \times 255 \times 3$ value for beginning the process of the approach. Then, the resized 20000 subimages were loaded to the software and with using normal images in the created Normal folder and Stroke patients in the created stroke folder and these folders were tagged clearly. Finally, via ANN\&LM model and CNN model interpretation was achieved in MATLAB 2019b. Generally, according to the 5-fold cross validation, training accuracy and loss values were given for ANN\&LM and CNN in Figure 12 and 13, respectively. 


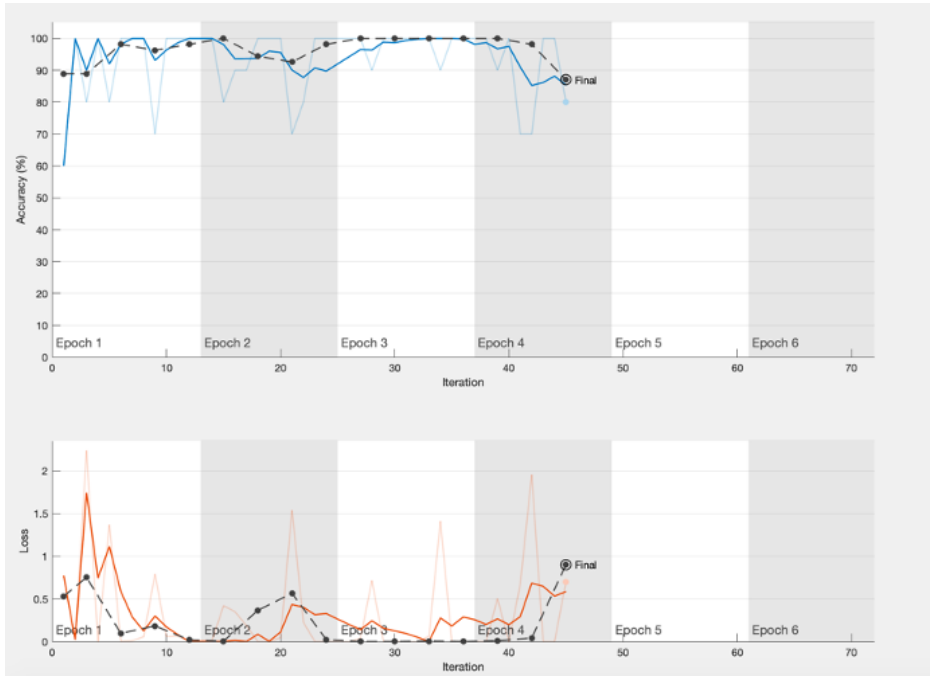

Fig. 12. Results for CNN model for DL part

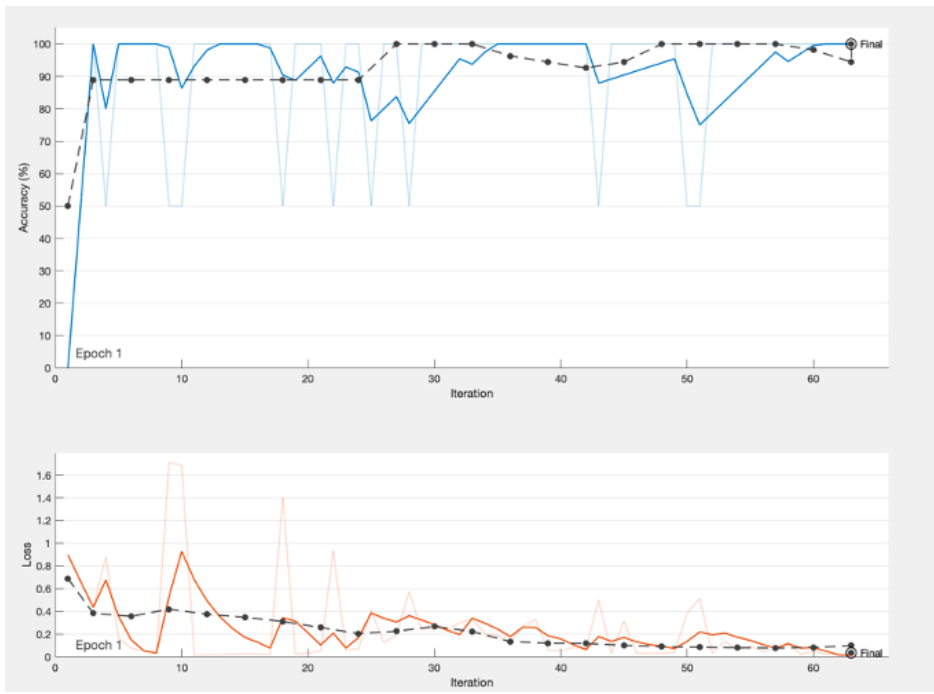

Fig. 13. Results for ANN\&LM model for AI part

According to the figures given above, two models were performed in different epochs, approximately; 5 epochs (CNN) and 6 epochs (ANN\&LM). Firstly, according to the Figure 12, the distribution of prediction of the data was changed slightly for the training $(\% 80)$ and test $(\% 20)$. When we investigate in detail, the prediction process continued for approximately the half of the total epochs and at the final stage, the result was stabilized in the value of $\% 90$, so according to the training process, for $\mathrm{CNN}$, the total prediction accuracy value was obtained as \%90. Secondly, according to the Figure 13, the distribution was shown with some fluctuation. Also, the fluctuation could be unstable and it was obvious that, the final of the model was concluded at the rate of $\% 98,5$, so the second highest performance was obtained from optimized AI model.

Moreover, the training loss outputs were given above in Figure 12 and 13 with red color, respectively. When the outputs of loss values for CNN and ANN\&LM models, loss values had an unstable fluctuation during the training stage. It could be said that in the graph of optimized model, loss values decreased rapidly and approached to zero value.

\section{Discussion}

Classical and modern CAD systems have some similarities and differences in some ways. Both of them are trained by using labelled data, this method can be classified as supervised learning. The labeling of the images is generally completed with a human expert. Besides the importance of this step to the process, the training dataset could be less prone to overfitting. However, large datasets are not easily obtained and also tagging/labelling process can be sometimes time-consuming. If there may be some errors in the images, this progress can be difficult and time-consuming for doctors and radiologists. Pattern Recognition process of the study in these methods, CAD medical systems can usually be used in preprocessing of medical images, detecting of ROI area and automatically extracting features from the imageset.

Knowledge of the size and case of an acute infarct is very crucial in clinical decision-making. In the presented study, a software adapted-based stroke diagnosis, scoring and interpretation system for early diagnosis of ishemic stroke was described in detail. Automated image analysis of ischemic stroke with the support of image processing, pattern recognition and decision processes were commercially achieved in this study. With the combination of these methods, the specific computer based diagnosis of (acute) stroke from CT images was attempted.

In this study, we presented two fundamental parts of our approach on brain CT images. The first part was detecting the abnormal areas in the brain with specific image processing methods in detail. The other part was evaluating, scoring and interpretation of the images of stroke suspected patients with using the optimized ANN\&LM model and CNN.

Indeed, a successfull attempt was also made to detect the case of hyperdense middle cerebral artery (MCA) dot sign among CT images. To accomplish some visually redundant areas, the Slyvian fissure region was automatically detected and the size parameters of this area was saved to the workspace. Then, after the center dot sign of the images was obtained, according to the size value the I, C, IC, L areas were clearly defined and obtained. Then, finally, the top and bottom last points were obtained and with using these, M1, M2, M3, M4, M5, M6 areas were clearly obtained on the CTs. There were totally 10 areas and each area was calculated as if ROI was obtained in the stroke area; 1 point was given to this evaluation. Otherwise, 0 point was given the final evaluation. A schematic diagram of the system and the accuracy analysis process are shown in Figure 14.

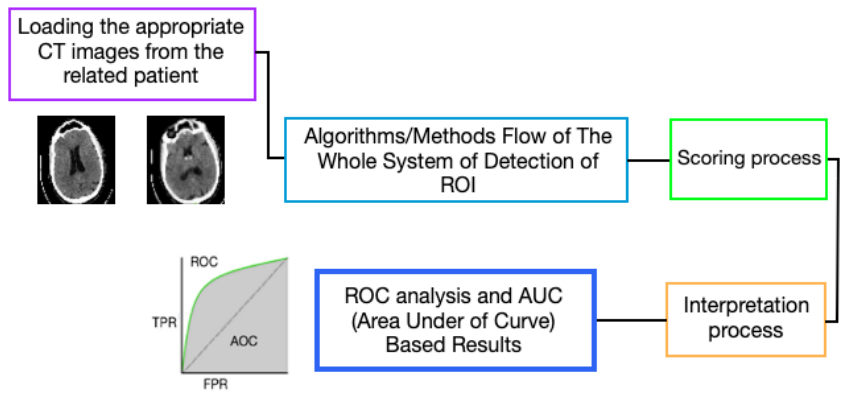

Fig. 14. Schematic diagram of the methods and the performance analysis of the system 
According to the experimentation, images were classified with important performance scores for all models. According to the ROC (Receiver Operating Characteristics) results, the accuracy results were obtained for $\mathrm{CNN}$ as $\% 90$ and for ANN\&LM as \%98,5, respectively. Some different ROC results were given in Figure 15.

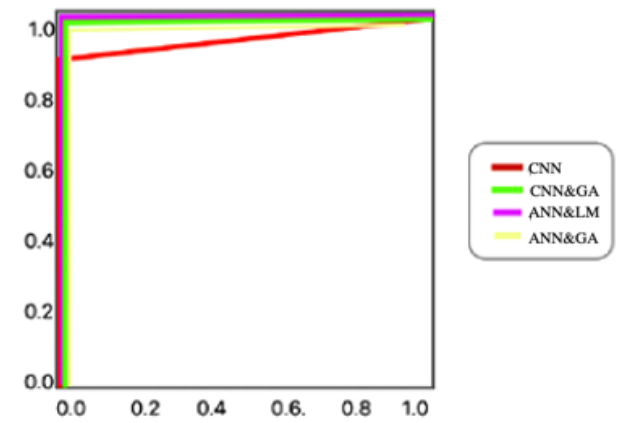

Fig. 15. Receiver Operating Characteristics (ROC) analysis results for the specific models

Table 1. Model Performance and Comparison Between CNN, ANN and the optimized version

\begin{tabular}{|l|l|l|l|l|}
\hline Model & $\begin{array}{l}\text { AUC } \\
\text { (Area } \\
\text { under } \\
\text { the } \\
\text { curve) }\end{array}$ & $\begin{array}{l}\text { DSC (Dice } \\
\text { score } \\
\text { coefficient) }\end{array}$ & Sensitivity & Specificity \\
\hline CNN & 0.90 & 0.59 & 0.55 & 0.98 \\
\hline CNN\&GA & 0.95 & 0.50 & 0.76 & 0.96 \\
\hline ANN\&LM & 0.985 & 0.46 & 0.80 & 0.95 \\
\hline ANN\&GA & 0.93 & 0.53 & 0.67 & 0.97 \\
\hline P value & $<.001$ & .002 & $<.001$ & $<.001$ \\
\hline
\end{tabular}

According to the performance metrics of the different specific methods, models used in this study (our proposed study), providing a comprehensive analysis and estimation of the (acute) stroke lesion that includes area of edema and hemorrhagic case, could serve as a marker for the patient selection in the prediagnosis area.

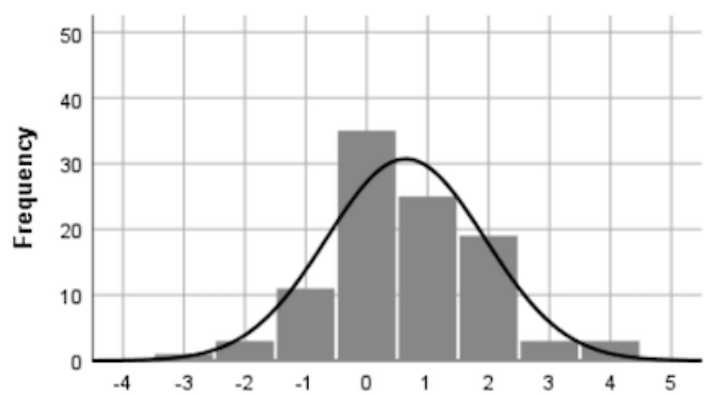

Fig. 16. Variation distribution of stroke detected images

Moreoever, data were analyzed from September 1, 2000 to August 1, 2021. Statistical analysis was achieved using Stata, Version 13.0 (StataCorp LLC). Paired sample Wilcoxon tests were performed to compare the area under the curve, DSC, sensitivity, specificity, lesion volume error. Concordance correlation coefficient ( $\mathrm{p}$ value) and Bland-Altman plots were also used to investigate the lesion volume predictions. Because infarct sizes were not normally distributed, cubic transformation was used for the concordance correlation calculation. Accoridng to Figure 16, the correlation was considered successful for $\mathrm{p}>$
0.65 , moderate for $\mathrm{p}=0.5$ to 0.65 and low for $\mathrm{p}<0.50$. Also, more shorter duration periods were obtained from the severe stroke patients than the moderate stroke patients, which indicates that these patients could have presented at an early stage of disease. This was also confirmed by the loss distribution of the data.

This section includes studies about stroke diagnosis. Table 2 presents all objectives on stroke diagnosis, DL techniques, features, sample size and result of the model. MRI and CT scans are generally used in stroke diagnosis. According to the table, it is obvious that our approach is significantly successful than the other related studies.

Table 2. Comparative Analysis For Stroke Detection Using Deep Learning Methods

\begin{tabular}{|c|c|c|c|c|}
\hline $\begin{array}{l}\text { Ref. } \\
\text { Number }\end{array}$ & $\begin{array}{l}\text { Authors } \\
\text { (Study) }\end{array}$ & Input data & Methods & Result \\
\hline [36] & $\begin{array}{l}\text { Biswas } \\
\text { M., } \\
\text { Kuppili } \\
\text { V., Araki } \\
\text { T. et al. } \\
\text { (2018) }\end{array}$ & $\begin{array}{l}\text { Ultrasound } \\
\text { images }\end{array}$ & $\begin{array}{l}\text { DLfor } \\
\text { segmentation }\end{array}$ & $\begin{array}{l}\text { Error on set } \\
\text { DL= } \\
0.126 \pm 0.134\end{array}$ \\
\hline [37] & $\begin{array}{l}\text { Bacchi } \\
\text { S., } \\
\text { Zerner T., } \\
\text { Oakden- } \\
\text { Rayner } \\
\text { L. et al. } \\
(2019) \\
\end{array}$ & $\begin{array}{l}\text { Brain CT } \\
\text { images }\end{array}$ & $\mathrm{CNN}, \mathrm{ANN}$ & $\begin{array}{l}\text { For } \\
\text { NIHSS24: } \\
\text { ACC }=0.71 ; \\
\text { For mRS90: } \\
\text { ACC }=0.74 \\
\text { F1 } \\
\text { scoe }=0.69\end{array}$ \\
\hline$[38]$ & $\begin{array}{l}\text { Ming } \\
\text { Sian, Lee } \\
(2014)\end{array}$ & $\begin{array}{l}\text { CT/MRI } \\
\text { images }\end{array}$ & Morphology & $\mathrm{AUC}=85 \%$ \\
\hline [39] & $\begin{array}{l}\text { Chiun-li- } \\
\text { Chin } \\
(2017)\end{array}$ & $\begin{array}{l}\text { CT/MRI } \\
\text { images }\end{array}$ & $\mathrm{CNN}$ & AUC $>90 \%$ \\
\hline [40] & $\begin{array}{l}\text { Arouj } \\
\text { Ahmed } \\
\text { Qureshi } \\
(2018) \\
\end{array}$ & EEG & $\begin{array}{l}\text { MLP and } \\
\text { Decision } \\
\text { Tree }\end{array}$ & AUC $=95 \%$ \\
\hline $\mathrm{X}$ & $\begin{array}{l}\text { Our } \\
\text { Approach }\end{array}$ & $\begin{array}{l}\mathrm{CT} / \mathrm{MRI} \\
\text { images }\end{array}$ & $\begin{array}{l}\text { AI } \\
\text { (optimized } \\
\text { ANN) and } \\
\text { DL (CNN) }\end{array}$ & $\begin{array}{l}\text { For AI: } \\
\text { AUC }>90 \% \\
\text { For DL: } \\
\text { AUC }>98.5 \%\end{array}$ \\
\hline
\end{tabular}

\section{Conclusions}

There were some limitations in the presented study. First, we could not have all of the CT scan data of every patients, so if we had, we could achieve more succesfull detection, evaluation and interpretation results. In the contrary, with using the limited number of dataset, we obtained highly important and successful results from the our approach. With using the limited number of data, we successfully used pre-trained Deep Learning models for fast detection and accurate evaluation. Last, although this software can be used commercially and this still needs radiologists' and doctors' supervision and advice.

There are some advantages of the study. The whole software has important advantages and these can help doctors for early diagnosis of (acute) ischemic stroke in addition to the area of $\mathrm{CAD}$ systems. According to the development process and the 
obtained results, it is important that this system can be more adapted with the Machine Learning, Artificial Intelligence methods as well as Deep Learning methods. In conclusion, this study can be developed for using with the other specific lesions in other parts of the human body, too.

\section{Conflicts Of Interest}

No conflict of interest was declared by the authors.

\section{References}

[1] Krittanawong, C., Zhang, H., Wang, Z., Aydar, M., Kitai, T., "Artificial Intelligence in Precision Cardiovascular Medicine", Journal of American College of Cardiology, 69(21):2657-2664, (2017).

[2] Bryan, R.N., Levy, L.M., Whitlow, W.D., Killian, J.M., Preziosi, T.J., Rosairo, J.A., "Diagnosis of acute cerebral infarction: comparison of CT and MR imaging", American Journal of Neuroradiology, 12(4):611-620, (1991).

[3] Tyan, Y.S., Wu, M.C., Chin, C.L., Kuo, Y.L., Lee, M.S., Chang, H.Y., "Ischemic stroke detection system with a computer-aided diagnostic ability using an unsupervised feature perception enhancement method", Journal of Biomedical Imaging, 19:9, (2015).

[4] Pexman, J.H.W., Barber, P.A., Hill, M.D., Sevick, R.J., Demchuk, A.M., Hudon, M.E., Hu, W.Y., Buchan, A.M., "Use of The Alberta Stroke Program Early CT Score (ASPECTS) For Assessing CT Scans In Patients With Acute Stroke", American Journal Of Neuroradiology, 22(8):15341542, (2001).

[5] Yoo, A.J., Zaidat, O.O., Chaudhry, Z.A., Berkhemer, O.A., Gonzales, R.G., Goyal, M., Demchuk, A.M., Menon, B.K., Mualem, E., Ueda, D., Buell, H., Sit, S.P., Bose, A., "Impact Of Pretreatment Noncontrast CT Alberta Stroke Program Early CT Score On Clinical Outcome After Intra-Arterial Stroke Therapy", Stroke, 45(3):746-751, (2014).

[6] Demchuk, A.M., Hill, M.D., Barber, P.A., Silver, B., Patel, S.C., Levine, S.R., "Importance Of Early Ischemic Computed Tomography Changes Using ASPECTS In Ninds Rtpa Stroke Study", Stroke, 36(10):2110-2115, (2014).

[7] Aviv, R.I., Mandelcorn, J., Chakraborty, S., Gladstone, D., Malham, S., Tomlinson, G., Fox, A.J., Symons, S., “Alberta Stroke Program Early CT Scoring Of CT Perfusion In Early Stroke Visualization and Assessment", American Journal Of Neuroradiology, 28 (10):1975-1980, (2007).

[8] Iihara, K., Nishimura, K. Kada, A., Nakagawara, J., Ogasawara, K., Ono, J., Shiokawa, Y., Aruga, T., Miyachi, S., Nagata, I., Toyoda, K., Matsuda, S., Miyamoto, Y., Suzuki, A., Ishikawa, K.B., Kataoka, H., Nakamura, F., Kamitani, S., "Effects Of Comprehensive Stroke Care Capabilities On In-Hospital Mortality Of Patients With Ishemic And Hemorrhagic Stroke: J-ASPECT Study", PLOS ONE, 9 (5), e96819, (2014).

[9] Herweh, C., Ringleb, P.A., Rauch, G., Gerry, S., Behrens, L., Möhlenbruch, M., Gotfort, R., Richter, D., Schieber, Nagel, S., "Performance Of e-ASPECTS Softare In Comparison To That Of Stroke Physicians On Assessing CT Scans Of Acute Ischemic Stroke Patients", International Journal Of Stroke, 11 (4):438-445, (2016).

[10] Puetz, V, Dzialowski, M., Hill, D., Demchuk, M., "The Alberta Stroke Program Early CT Score in Clinical Practice:
What have We Learned", International Journal of Stroke, 4(5):354-364, (2019).

[11] Ural, B., Özışık, P., Hardalaç, F., “An Improved Computer Based Diagnosis System For Early Detection Of Abnormal Lesions In The Brain Tissues With Using Magnetic Resonance and Computerized Tomography Images", Multimedia Tool and Applications, (2019).

[12] Ural, B., "A Computer-Based Brain Tumor Detection Approach with Advanced Image Processing and Probabilistic Neural Network Methods", Journal of Medical and Biological Engineering, 38(6):867-879, (2018).

[13] Jeena, R.S., Kumar, S., “A comparative analysis of MRI and CT brain images for stroke diagnosis", 2013 Annual International Conference on Emerging Research Areas and 2013 International Conference on Microelectronics, Communications and Renewable Energy, Kanjirapally, 1-5, (2013).

[14] Rajini, N.H., Bhavani, R., "Computer Aided Detection of Ischemic Stroke Using Segmentation and Texture Features", Measurement, 46(6): 1865-1874, (2013).

[15] Ali, S.M., Abood, L.K., Abdoon, R.S., "Brain Tumor Extraction in MRI images using Clustering and Morphological Operations Techniques", International Journal of Geographical Information System Applications and Remote Sensing, 4(1), (2013).

[16] Georgantzoglou, A., Silvia, J., Jena, R., "Image Processing with MATLAB and GPU-Open access peer reviewed chapter". September, (2014).

[17] Saini, L.K., Shrivastava, V., "Analysis of Attacks on Hybrid DWT-DCT Algorithm for Digital Image Watermarking With MATLAB", Cryptography and Security, 2(3):123125, (2014).

[18] Suzuki, H., Toriwaki, J., "Automatic Segmentation Of Head MRI Images By Knowledge Guided Thresholding", Computerized Medical Imaging and Graphics, 15(4): 223 240, (1991).

[19] Yu-qian, Z., Wei-hua, G., Zhen-cheng, C., Jing-tian, T., Ling-yun, L., "Medical Images Edge Detection Based on Mathematical Morphology", IEEE Engineering in Medicine and Biology 27th Annual Conference, (2005).

[20] Yuskevich, P.A., Piven, J., Hazlett, H.C., Smith, R.G., Ho, S., Gee, J.C., Gerig, G., "User-Guided 3D Active Contour Segmentation Of Anatomical Structures: Significantly Improved Efficiency And Reliability", NeuroImage, 31(3):1116-1128, (2006).

[21] Dhawan, A. P., Chitre, Y., Kaiser-Bonasso, C., "Analysis Of Mammographic Microcalcifications Using Gray-Level Image Structure Features", IEEE Transactions on Medical Imaging, 15(3), (1996).

[22] Sujji, G.E., Lakshmi, Y.V.S., Jiji, G.W., "MRI Brain Image Segmentation Based On Thresholding", International Journal of Advanced Computer Research, 3(1), (2013).

[23] Yuncong, F., Haiying, Z., Xiongfei, L., Xiaoli, Z., Hongpeng, L., "A Multi-Scale 3D Otsu Thresholding For Medical Image Segmentation”, Digital Signal Processing, 60, 186-199, (2017).

[24] Manikandan, S., Ramar, K., Ihuthayarajan, M.W., Srinivasagan, K.G., "Multilevel Thresholding For Segmentation Of Medical Brain Images Using Real Coded Genetic Algorithm", Measurement, 47, 558-568, (2014).

[25] Ming-Ni, W., Chia-Chen, L., Chin Chen, C., "Brain Tumor Detection Using Color-Based K-Means Clustering Segmentation", IEEE Third International Conference on 
Intelligent Information Hiding and Multimedia Signal Processing, (2017).

[26] Dzialowski, I., Hill, M.D., Coutts, S.B. Demchuk. A.M., Kent, D.M., Wunderlich, O., vom Kummer, R., "Extent of Early Ischemic Changes on Computed Tomography (CT) Before Thrombolysis”, Stroke, 37(4):973-978, (2006).

[27] Chen, C.W., Luo, J., Parker, K.J., "Image Segmentation via Adaptive $\mathrm{K}$ mean Clustering and Knowledge-Based Morphological Operations with Biomedical Applications", IEEE Transactions on Image Processing, 7(12):1673- 1683, (1998).

[28] Hassoun, M. "Fundamentals of Artificial Neural Networks", MIT Press, (A Bradford Book), (2003).

[29] Gonzales, R.C., Woods, R.E. "Digital Image Processing 4th Edition", (2017).

[30] Mehdy, M.M., Ng, P.Y., Shair, E.F., Md Saleh, N.I., Gomes, C., "Artificial Neural Networks in Image Processing for Early Detection of Breast Cancer" Computational and Mathematical Methods in Medicine, (2017).

[31] Shenbagarajan, A., Ramalingam, V., Balasubramanian, C., Palanivel, S., "Tumor Diagnosis in MRI Brain Image using ACM Segmentation and ANN-LM Classification Techniques", Indian Journal of Science and Technology, 9(1), (2016).

[32] Khehra, B.S., Pharwaha, A.P.S., "Classifcation of Clustered Microcalcifications Using A MLFFBP-ANN and SVM", Egyptian Informatics Journal, 17(1):11-20, (2016).

[33] Sankupellay, M., Konovalov, M., "Bird Call Recognition Using Deep Convolutional Neural Network, ResNet-50", Acoustics, (2018).

[34] Macêdo, D., Zanchettin, C., Oliveira, A., Ludermir, T., "Enhancing Batch Normalized Convolutional Networks Using Displaced Rectifier Linear Units: A Systematic Comparative Study", Expert Systems with Applications, 124, 271-281, (2019).

[35] Kawahara, J., Hamarneh, G., "Multi- Resolution-Tract CNN with Hybrid Pretrained and Skin-Lesion Trained Layers, In: Wang L, Adeli E, Wang Q, Shi Y, Suk HI. (eds) Machine Learning in Medical Imaging (MLMI)", Lecture Notes in Computer Science. 10019, Springer, Cham, (2016).

[36] Biswas, M., Kuppili, V., Araki, T., Edla, D.R., Godia, E.C., Suri, H.S., Omerzu, T., Laird, J.R., Khanna, N.N., Nicolaides, A., Suri J.S., "Deep learning strategy for acute carotid intima-media thickness measurement: an ultrasound study on japanese diabetic cohort", Computers in Biology and Medicine. 98:100-117, (2018).

[37] Bacchi, S., Zerner, T., Oakden-Rayner, L, Kleinig, T., Patel, S., Jannes, J., "Deep learning in the prediction of ischemic stroke thrombolysis functional outcomes: A pilot study", Academic Radiology, (2019).

[38] Tyan, Y.S., Ming-Chi, W., Chiun-Li, C., Yu-Liang, K., Ming-Sian, Lee, Hao,Yan, C., "Ischemic stroke detection system with a computer aided diagnostic ability using an unsupervised feature perception enhancement method", Internatinal Journal of Biomedical Imaging, (2014).

[39] Chen-Ying, H., Wei-Chen, C., Po-Tsun, L., Chin-Heng, L., Chi-Chun, L., "Comparing deep neural networks and other machine learning algorithms for stroke prediction in a large scale population-based electronic medical claims database", In $201739^{\text {th }}$ Annual International Conference of the IEEE Engineering in Medicine and Biology Society (EMBC), 3110-3113, (2017).
[40] Qureshi, A.A., Canxiu, Z., Rong, Z. and Elmeligi, A., "Ischemic stroke detection using EEG signals", In Proceedings of the $28^{\text {th }}$ Annual International Conference on Computer Science and Software Engineering. 301-308, (2018). 